\title{
Drive simulation tests for electric drilling rig
}

\author{
Krzysztof Kotwica, Grzegorz Stopka \\ AGH University of Science and Technology, Poland
}

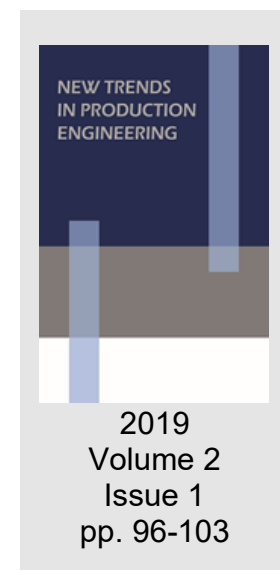

Date of submission to the Editor: 05/2019

Date of acceptance by the Editor: 07/2019

\section{INTRODUCTION}

Battery technology is ideally suited for underground mining. In recent years, the use of electric drive in mining machines is one of the new directions of research. Replacing diesel drive with battery drive brings the broad range of benefits, especially taking into consideration conditions of underground mining. As is generally known, the use of battery drive leads to the total elimination of diesel fine particular matter and other exhaust gas components in the underground environment. Secondly, elimination of diesel drive in mining machines causes reduction of noise and vibration level. As the third, the heat emission to mine atmosphere can be reduced. These influence on reducing of the energy consumption of the mining process, and in particular the reduction of mine ventilation costs. In addition, in excavations located at low operating levels, the air conditioning of the operator's cabin is insufficient with the current level of heat emission. Implementation of battery drive in mining machines is one of the factors allow to lessen the ambient temperature (Paraszczak et al., 2014, Kotwica et al., 2017, Schatz et al., 2018). Taking into consideration the abovementioned, Mine Master company in cooperation with AGH University of Science and Technology and Wroclaw University of Science and Technology attempted to develop an innovative construction of drilling rig and bolting rig with battery drive. Research in this field were conducted under the project no. POIR.01.01.01-00-D011/16 entitled „New generation of modular rigs, drilling and bolting, with battery drives, designated to work in underground cooper ore and raw rock material mines". The project is funded by the National Center of Research and Development (NCBiR, Poland). The aim of the project was to design and implementation of innovation drilling and bolting rig with electric drive system. As part of the first phase of the project simulation tests of a battery and a diesel drive systems were planned. The main issues of modeling and research in this field were identification traction parameters of designed drive system and verification the battery drive system by comparison to the diesel drive system. Due to the large number of construction parameters, it was necessary to use 
computer simulations. The use of computer simulation for the analysis of mining machines is often the only method of design verification (Gospodarczyk et al 2016, Mendyka et al 2016, Feliks 2017, Bołoz et al 2018, Stopka 2019). Due to the complexity of the structure of the drive system (mechanical, hydraulic and electrical elements), it was necessary to use advanced simulation software dedicated to multiphysics analysis.

Dynamic behavior of vehicles can be analysed in several different ways (Kıyaklı et al 2018, Tomasikova et al. 2018). To develop a computation model, and then to conduct simulation tests of the drive systems, Simulation $X$ program was used. This approach allowed to elaborate complex simulation models. The basis for the parameterization of the simulation models was a real construction of Face Master 1.7L. The results of simulation tests have been used to identify significant traction parameters of machines as a function of road conditions. The described method of drilling rig simulation tests can be integrated with the Multibody simulation method (MBS). It gives a wide range of model research possibilities for this type of technical objects.

\section{SIMULATION OBJECT}

The object of simulation tests was the drilling rig chassis. Currently, in constructions of these machines, a hydrostatic drive system is commonly used. The most common drive system is consists of a main pump and 4 hydraulic motor, which converts fluid flow under pressure into rotating torque on the output shaft. The wheels of drilling rig are mounted on the shafts of the hydraulic motors. The hydrostatic drive system is powered by diesel engine. An example of the arrangement of the hydrostatic drive system components in Face Master 1.7L is shown on Figure 1, 2.

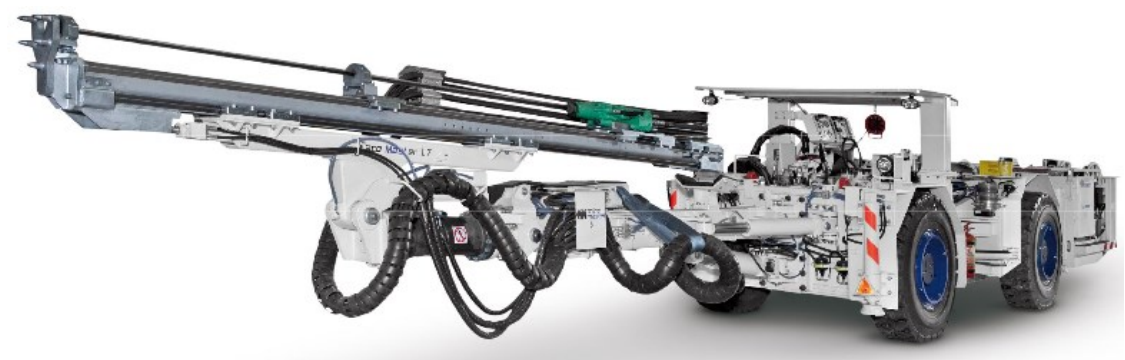

Fig. 1 Drilling rig Face Master 1.7L

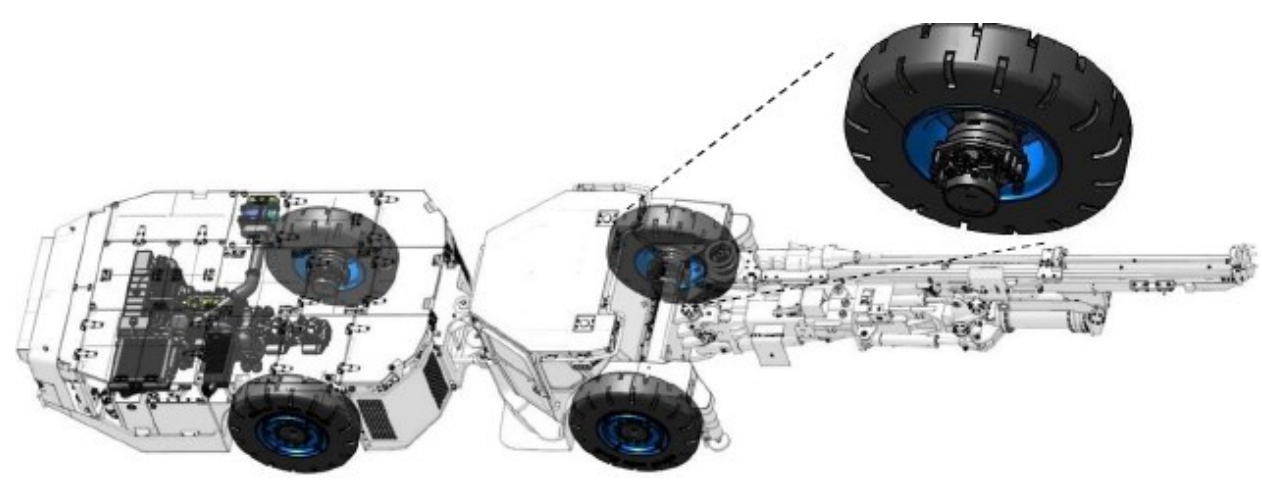

Fig. 2 Components of the hydrostatic drive system in Face Master 1.7L 
The driving unit of Face Master 1.7L is diesel engine TCD 2012 (100 kW). The clutch is mounted on the output shaft of the diesel engine and transmits power form the engine to the pomp unit. The pomp unit powered 4 hydraulic motors, that are integrated with the wheels of the drilling rig. The main parameters that have been used in simulations are presented in the Table 1.

Table1 Main parameters used in the simulation of the drive systems of Face Master $1.7 \mathrm{~L}$

Parameter

Total mass
Wheel diameter
Wheel space
Max. displacement of hydraulic motors - front axie
Max. displacement of hydraulic motors - rear axie
Max. displacement of hydraulic pump - front axie
Max. displacement of hydraulic pump - rear axie
Power of diesel engine
Power of electric engine

Value

$21500 \mathrm{~kg}$

$1.24 \mathrm{~m}$

$3.5 \mathrm{~m}$

$4198 \mathrm{~cm}^{3} / \mathrm{rev}$

$2812 \mathrm{~cm}^{3} / \mathrm{rev}$

$100 \mathrm{~cm}^{3} / \mathrm{rev}$

$100 \mathrm{~cm}^{3} / \mathrm{rev}$

$90 \mathrm{~kW}(2300 \mathrm{RPM})$

$90 \mathrm{~kW}(2200 \mathrm{RPM})$

The essence of replacing diesel drive with battery drive in drilling and bolting rigs is the replacing a diesel engine with an electric engine, which will be powered by a battery unit. In order to previous verification of the new drive system assumed that the structure and parameters of hydrostatic drive system will be remained immutable in relation to the chassis of Face Master 1.7L. As a starting point for the consideration of technical parameters of the new drive system, the hydrostatic drive system of Face Master 1.7L was adopted. The structure of Face Master 1.7L drive system was the base of elaboration simulation models that have been used to comparative simulation tests between the battery and diesel drive system in selected road conditions.

\section{TESTING METHODOLOGY}

On the base of the collected data regarding the structure and parameters of the hydrostatic drive system and based on the results of work consisting in the identification of mathematical models of components of the drive system, simulation models of the drive systems were developed. To develop a computation model, and then to conduct simulation tests of drive systems, the Simulation $X$ program was used. The structure of simulation models are shown in Figures $3 \mathrm{i} 4$. These models are divided into several blocks (sub-models), that can be treat as basic component of the driver system. Each of blocks is defined by mathematical model for the description of physical properties and can be connected with each other through specific physical connections (mechanical, hydraulic and electrical.). For example the engine block consists of the submodel of an engine, that allows to define mechanical specification of an engine and the signal block, that can be use to model a control system of an engine. The engine block has been marked in red color, as is illustrated in Figures 3 i 4. The pumps block has been marked in turquoise color. The wheel block (gray color) consists of driving elements (engines), contact elements and signal blocks, that allows to simulate different road conditions. 


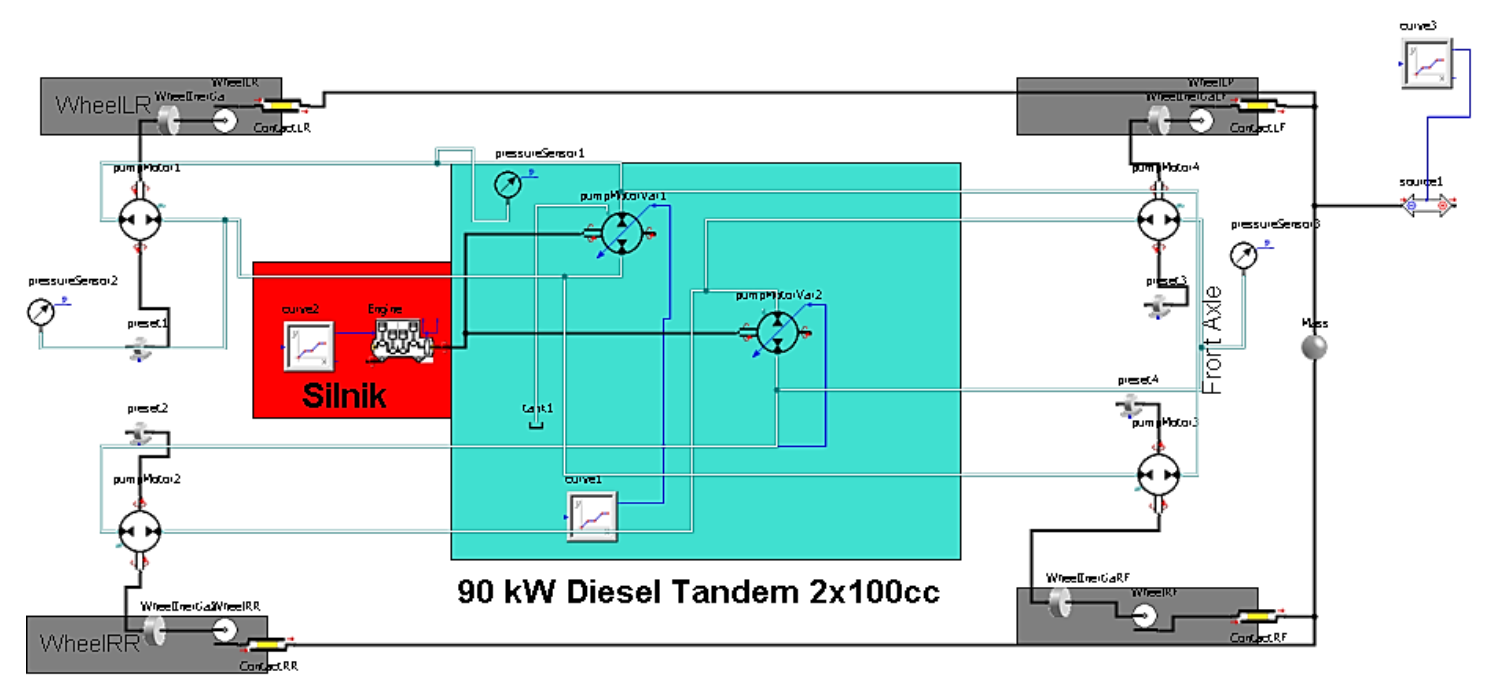

Fig. 3 Simulation model of the diesel drive system

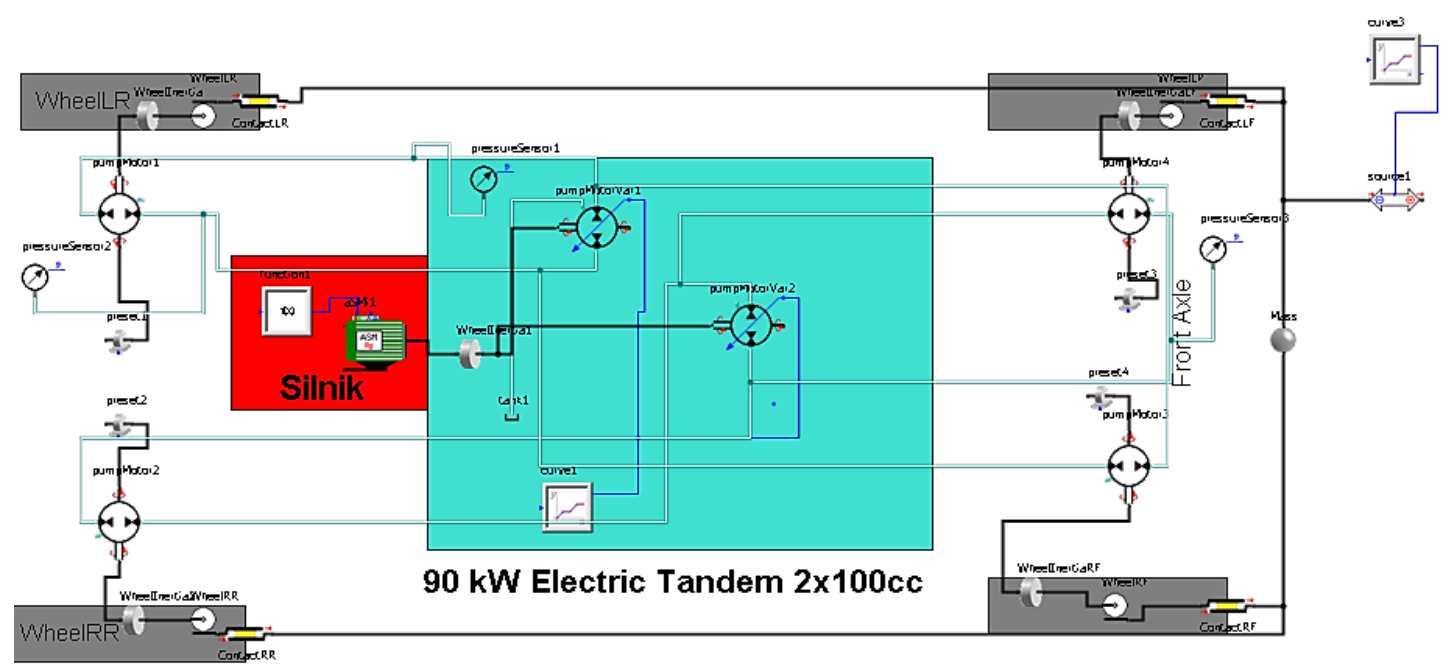

Fig. 4 Simulation model of the electric drive system

In addition the simulation model includes the block that is dedicated to generate geometrical and physical parameters of parts such as mass or solid moment of inertia. In order to apply boundary condition like loads, resistances to motion or route profiles the special functional blocks have been used. In selected points of the model sensors measure relevant mechanical and hydraulic parameters of tested driving systems.

Conducted research included many tests of the diesel and the electric drive system for wide range of parameters related to resistance to motion and a characteristic of route profile. In the first phase of analysis the test drive was carried out. This test assumed that the machine is moving on a horizontal road. The results of the test was a verification of the drive system in terms of resistance to motion. Due to uneven mass distribution between front and rear axle of the drilling rig the motion resistance forces have been calculated separately for each wheel. In the simulations the forces of inertia and the efficiency of driving units were taken account. The main issue of research was to verify the driving system of the drilling rig in case of driving uphill. During simulations the slope angle of a road was systematic increasing every 2 degree, so as to finally reaches the value of $10^{\circ}$. 


\section{RESULTS OF SIMULATION TESTS}

As it was mentioned above the main issues of modeling and research were identification traction parameters of designed drive system and verification the battery drive system by comparison to the diesel drive system. In addition obtained results of simulation allow to identify the impact of road conditions (e.g. inclination) to the traction parameters of the new construction of drilling rig. In Figures 5-8 exemplary courses of displacement, velocity and acceleration of the drilling rig are presented. In Figures 5 and 6 the results of simulation tests of the diesel drive system are shown.

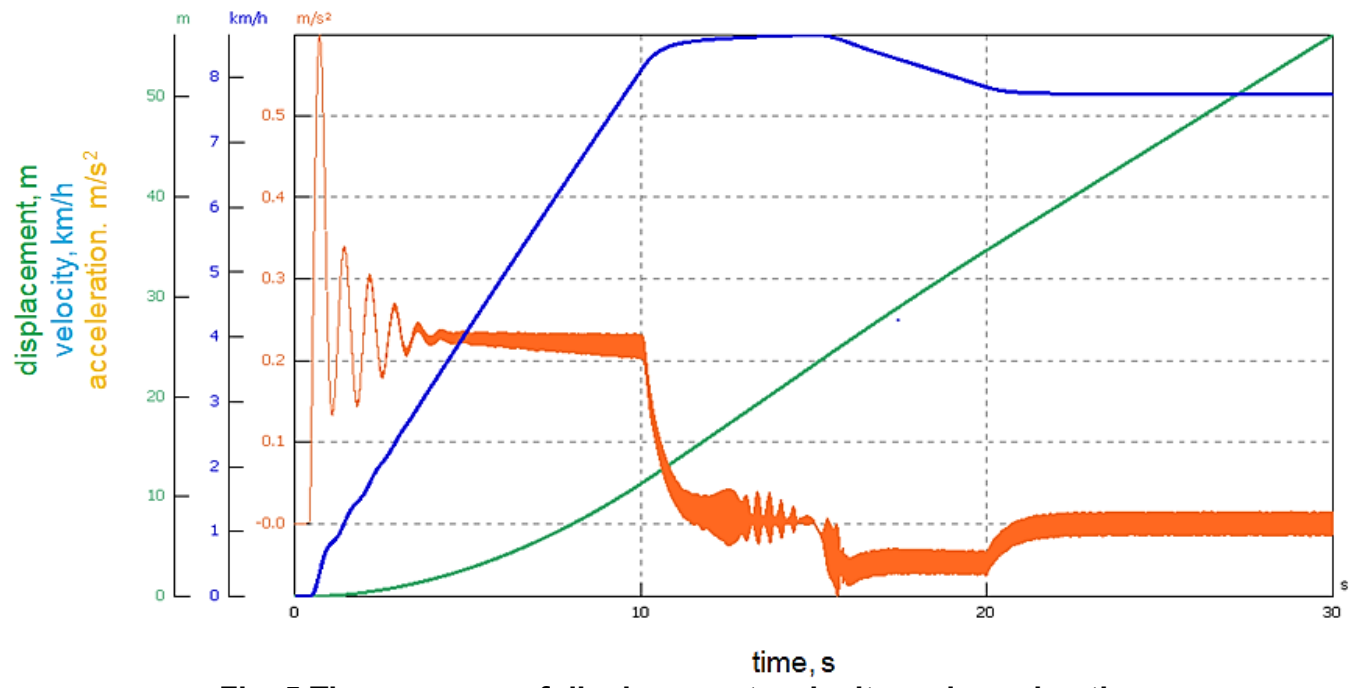

Fig. 5 Time courses of displacement, velocity and acceleration for the drilling rig with diesel drive system (inclination $-2.5^{\circ}$ )

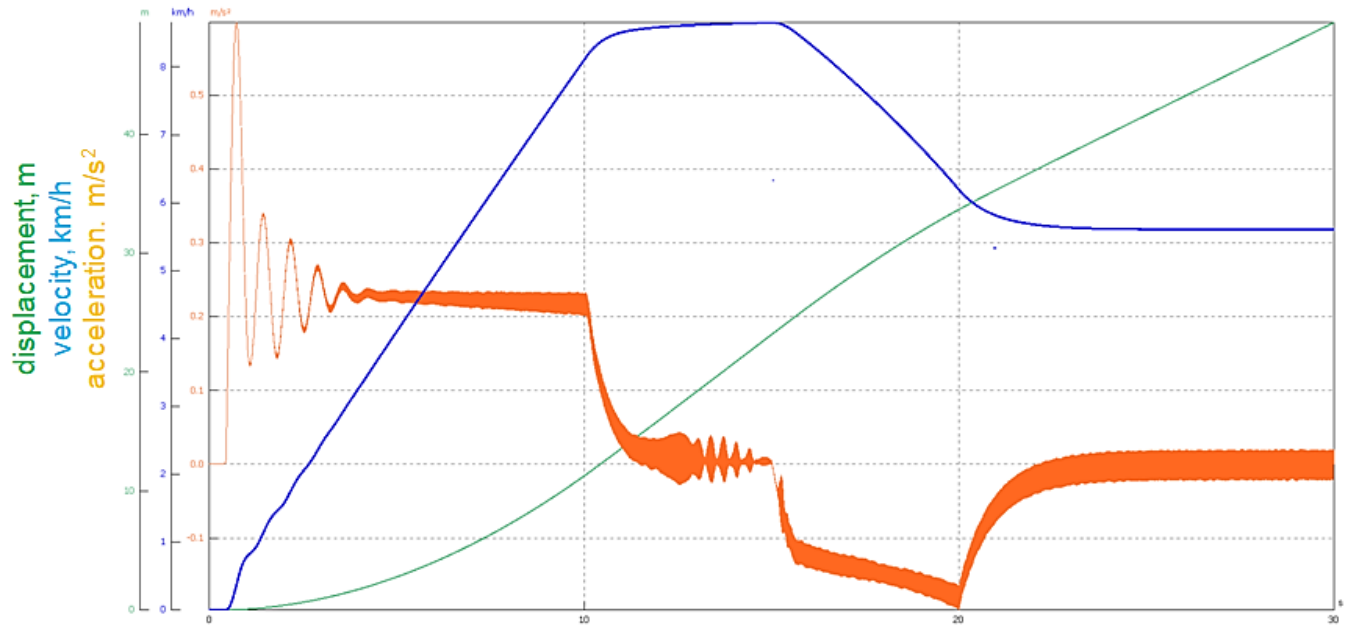

time, $s$

Fig. 6 Time courses of displacement, velocity and acceleration for the drilling rig with diesel drive system (inclination $-10^{\circ}$ )

The results of tests for the electric drive system are shown in Figures 7 and 8 . Each simulation test of driving systems was divided into two phases. In the first phase of the test the machine was moving on a horizontal road until it reaches the nominal driving parameters. After fifteen seconds of the test the machine enters on the road that is inclined at selected angle. 


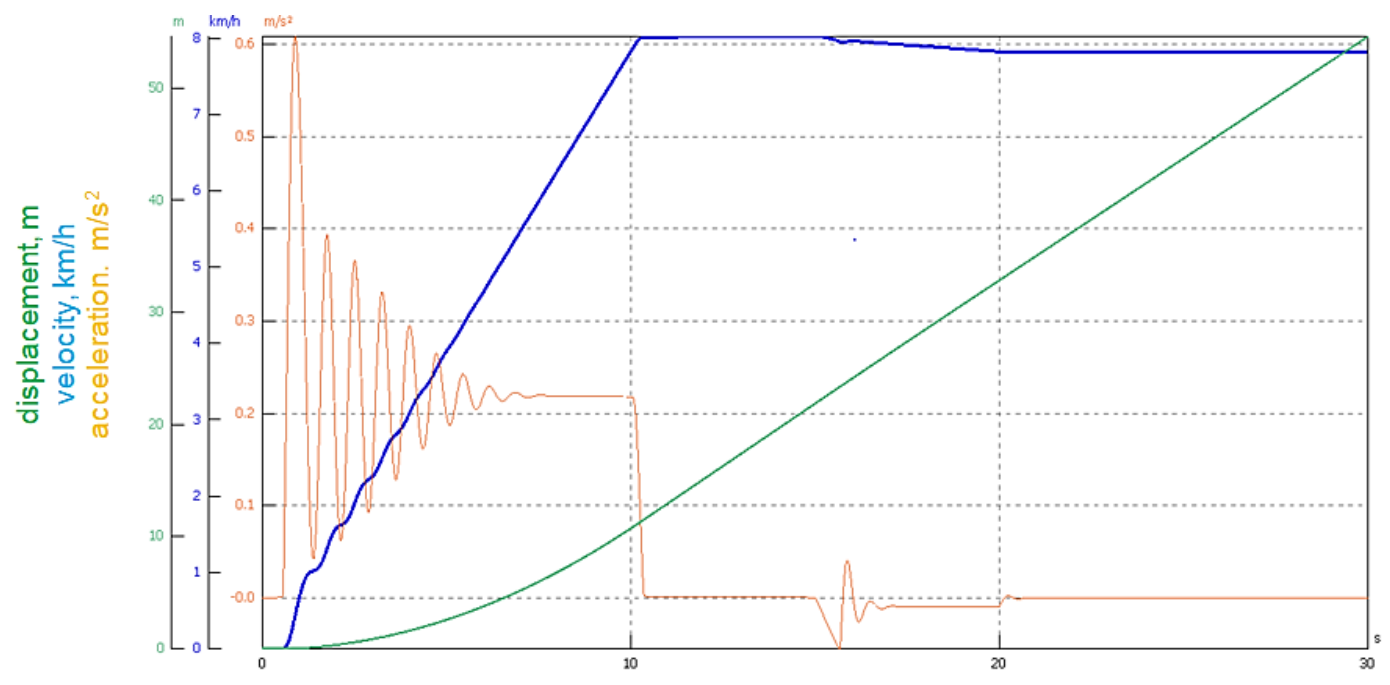

time, s

Fig. 7 Time courses of displacement, velocity and acceleration for the drilling rig with electric drive system (inclination $-2.5^{\circ}$ )

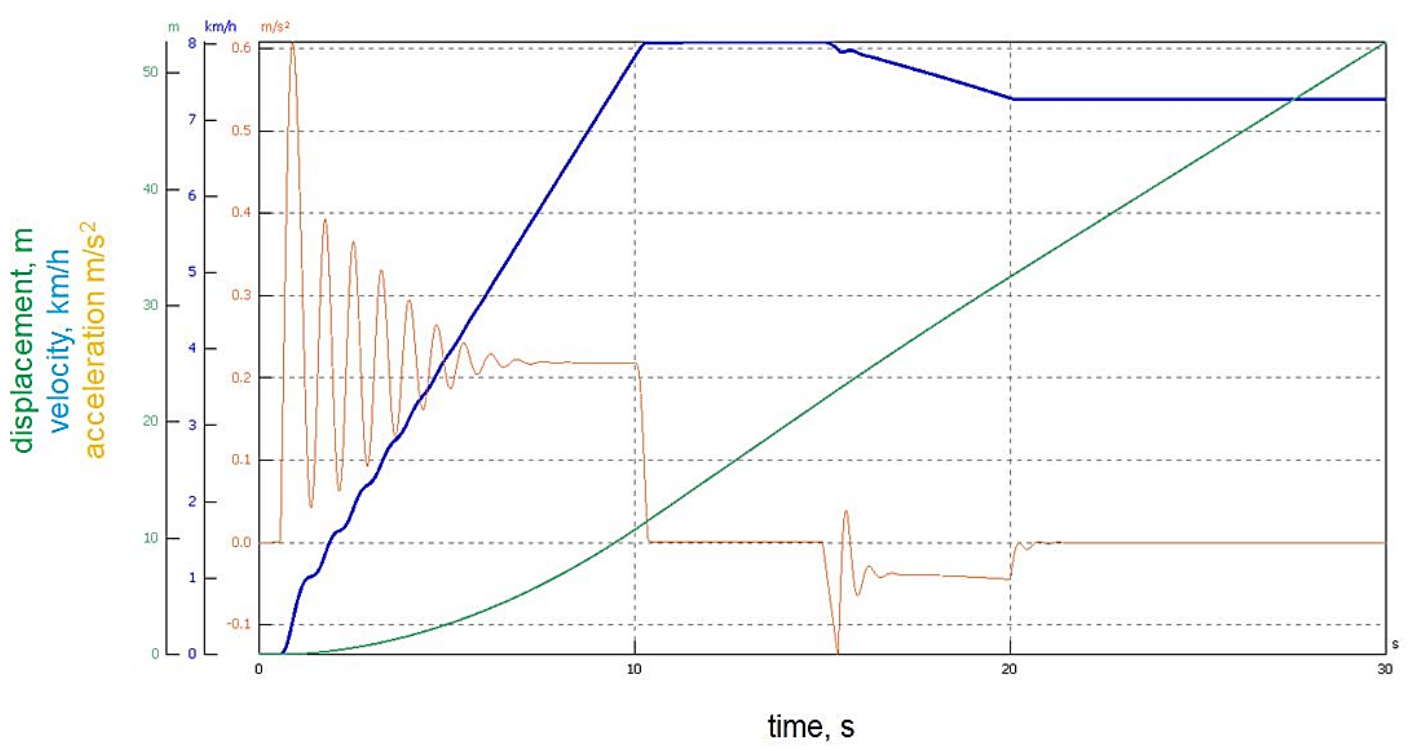

Fig. 8 Time courses of displacement, velocity and acceleration for the drilling rig with electric drive system (inclination $-10^{\circ}$ )

The conducted research allowed to compare the impact of various characteristics of drive units and boundary conditions (resistance to motion) on the traction characteristics of a new construction of drilling rig. As a result of the simulation tests performed the correlation between velocity of the drilling rig and the resistance to motion was identified. In the maximum angle of inclination (10 $\mathrm{deg}$ ) the diesel vehicle reaches the velocity of $5.3 \mathrm{~km} / \mathrm{h}$, while the electric vehicle reaches the velocity of $7.4 \mathrm{~km} / \mathrm{h}$. On the base on conducted tests and taking into consideration characteristic of the coursers of measured parameters, it can be said that the use of electric drive system allows to improve traction properties of the drilling rig, as it is illustrated in Figure 9. 


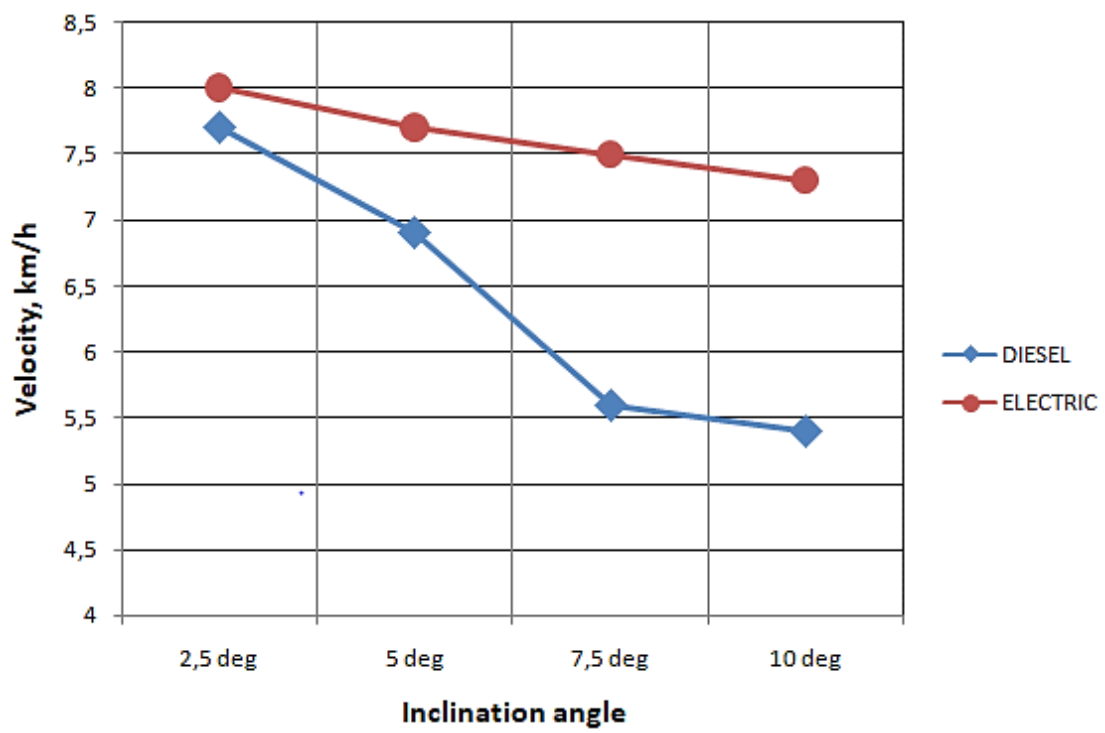

Fig. 9 Comparison between the electric and diesel drive system

\section{SUMMARY AND CONCLUSIONS}

The finale result of simulations was positive verification of the applicability the electric dive system in a new construction of drilling rig. The presented simulation models have been used for detailed analisys in terms of selection of technical characteristics of components of the electric drive system.

Due to the complexity of the structure of the drive system (mechanical, hydraulic and electrical elements), it was necessary to use advanced simulation software dedicated to multiphysics analysis. The use of Simulation $X$ allows to develop multiphisic models of the drilling rig. The method presented provides opportunities for virtual prototyping during the process of designing a construction of a chassis of drilling and bolting rigs. Data presented in the article can be used as guidelines in design process of drilling and bolting rigs as well as in optimization their driving system and mechanical construction.

\section{ACKNOWLEDGEMENTS}

The project has been subsidized by the National Center for Research and Development (POIR.01.01.01-00-D011/16).

\section{REFERENCES}

Bołoz Ł., Leonel F. Castañeda: Computer-aided support for the rapid creation of parametric models of milling units for longwall shearers, Management Systems in Production Engineering, 26(4), pp. 193-199.

Gospodarczyk P, Kotwica K., Mendyka P., Stopka G., Bołoz Ł.: The design and analisys of drilling and bolting rigs for narrow vein exploitation, " Exploration and mining, mineral processing. International Multidisciplinary Scientific GeoConference SGEM, vol. 2" Sofia 2016, p. 881-888

Feliks J.: Badania i modelowanie wibracyjnych grudkowników rynnowych - Research and modeling of vibratory chute clump-producing device/. Kraków: Wydawnictwa AGH, ISBN: 978-83-7464-920-9, Kraków 2017

Mendyka P., Stopka G., Gospodarczyk P., Bołoz Ł.: Analiza dynamiczna konstrukcji wozów wiercącego i kotwiącego specjalnego zastosowania. Transport przemysłowy 4/2016 
Kotwica K., Mendyka P., Czajkowski A., Ostapow L., Kozłowki A.: The possibility of battery drive application in mining drilling. SGEM 2017 17th international multidisciplinary scientific geoconference: science and technologies in geology, exploration and mining. Vol. 17 iss. 13, Exploration and mining. ISBN: 978-6197105-00-1, Sofia 2017, p. 917-924.

Kıyaklı A., Hamit S.: Modeling of an Electric Vehicle with MATLAB/Simulink. International Journal of Automotive Science And Technology, 2018, vol. 2 No: 4, 9-15

Paraszczak J., Svedlund E., Fytas K, Laflamme M.: Electrification of Loaders and Trucks - A Step Towards More Sustainable Underground Mining. Renewable Energy and Power Quality Journal, ISSN 2127 -038X, No 12, April 2014.

Stopka G.: Numerical simulation in design process of the new generation mining head with disc tools. Systemy Wspomagania w Inżynierii Produkcji; ISSN 2391-9361. 2019 vol. 8 iss. 1 Górnictwo - perspektywy i zagrożenia, s. 164-172

Schatz R., Nieto A., N. Lvov, S. Dogruoz, C.: Using Modern Battery Systems in Light Duty Mining Vehicles: International Journal of Mining Reclamation and Environment. DOI 10.1080/17480930.2013.866797. 2015/08/01

Tomasikova M., Brumerčík f., Nieoczym A.: Design and dynamics modeling for electric vehicle. 19 Applied Computer Science, vol. 13, no. 3, pp. 19-31doi: 10.23743/acs2017-18

Mine Master Ltd., website: https://www.minemaster.eu/pl/pl

\begin{abstract}
.
The article presents methodology and selected results of simulation tests of diesel and electric dive system for drilling rig. Research in this field were conducted under the project no. POIR.01.01.01-00-D011/16 entitled "New generation of modular rigs, drilling and bolting, with battery drives, designated to work in underground cooper ore and raw rock material mines". The project is funded by the National Center of Research and Development (NCBiR). The aim of the project is to design and implementation of innovation drilling and bolting rig with electric drive system. Due to the complexity of the structure of the drive system (mechanical, hydraulic and electrical elements), it was necessary to use advanced simulation software dedicated to multiphysics analysis. Data presented in the article can be used as guidelines in design process of drilling and bolting rigs as well as in optimization their driving system and mechanical construction.
\end{abstract}

Keywords: drilling rig, bolting rig, electric drive system, dynamic simulation 